\title{
Anti-Gastrins Antiserum Combined with Lowered Dosage Cytotoxic Drugs to Inhibit the Growth of Human Gastric Cancer SGC7901 Cells in Nude Mice
}

\author{
Qing $\mathrm{He}^{1,2}$, Hua Gao ${ }^{1}$, Meng Gao ${ }^{3}$, Shengmei Qi ${ }^{3}$, Yingqi Zhang ${ }^{\circledR}$, Junzhi Wang ${ }^{1,2} \bowtie$ \\ 1. Biotechnology Center, Department of Pharmacy, Fourth Military Medical University, Xian, China; \\ 2. National Institutes for Food and Drug Control, Beijing, China; \\ 3. OnkoRx Ltd., Beijing, China.
}

\begin{abstract}
$\triangle$ Corresponding author: Prof. Junzhi Wang, PhD. National Institutes for Food and Drug Control. Address: No. 2, Tiantan Xili, Chongwen District, Beijing. Post code and country: 100050, China. Tel: 0086-10-67095782; Fax: 0086-10-67014382; E-mail: wangiz@nifdc.org.cn or Prof. Yingqi Zhang, PhD. Biotechnology Center, Department of Pharmacy, Fourth Military Medical University. Address: No. 169, Changle West Road, Xian. Post code and country: 710032, China. Tel: 0086-29-84774773; Fax: 0086-29-83247213; E-mail: zhangyqh@fmmu.edu.cn.
\end{abstract}

() 2015 Ivyspring International Publisher. Reproduction is permitted for personal, noncommercial use, provided that the article is in whole, unmodified, and properly cited. See http://ivyspring.com/terms for terms and conditions.

Received: 2014.12.20; Accepted: 2015.02.01; Published: 2015.03.08

\begin{abstract}
The objective of this study was to determine the effect of anti-gastrin antiserum in combination with varied dosages of cytotoxic drugs (5-Fluorouracil (5FU) + Cisplatin (CDDP)) in vivo growth of the human gastric cancer cell-line, SGC-7901, which expressed cholecystokininB/gastrin receptors and secreted gastrin. The anti-gastrin antiserum was obtained by immunizing rabbits using a novel immunogen vaccine, which was composed of the common amino-terminal portion of human carboxy-amidated gastrin-17 (G17) and glycine-extended gastrin-17 (gly-G17) and the common carboxy-terminal portion of progastrin (in a 50:50 mixture) all covalently linked to tetanus toxoid (TT) by specific peptide spacers. The antiserum neutralized both $\mathrm{G} 17$ and gly-G17 by enzyme-linked immunosorbent assay (ELISA), and a synthetic progastrin peptide, as well, using an $E$. coli expressed his-tagged progastrin.

The tumor was implanted subcutaneously into the backside of BALB/c nude mice, and the combination antibody-drug treatment using low dose combination chemotherapy had significantly reduced median tumor volumes $(62 \%$ reduction; $p=0.0018)$ and tumor weights $(53 \%$ reduction; $p$ $=0.0062$ ) when compared to the conventional high dose chemotherapy treated control mice that had a corresponding similar reductive effect, using just the two standard cytotoxic drugs alone; namely by reducing the tumor volumes $(65 \% ; p=0.0016)$ and tumor weights $(59 \%$ reduction; $p=0.0033$ ). Importantly, the immunological treatment had little of the toxicities and side-effects of the full chemotherapy doses alone, which was effected by using a significant decrease in the dosage of chemotherapeutic drugs, while maintaining the same level of efficacy at reduction of tumor growth.
\end{abstract}

Key words: Gastrins; Progastrin; Cancer; Cytotoxic Drugs; Antibody.

\section{Introduction}

Gastrins are peptide hormones secreted by G cells in antrum of stomach and mucosal membrane. Gastrin's post-translational processing is from a gastrin precursor, preprogastrin, which gives rise to a variety of products including progastrin (pro-G), glycine-extended gastrin-34 (gly-G34), amidated gas- trin-34 (G34), glycine-extended gastrin-17 (gly-G17) and amidated gastrin-17 (G17), each with a distinctive spectrum of biological activity. Progastrin itself stimulates colonic epithelial proliferation, and their bioprocessed intermediates (Gly-extended progastrins and gastrins) stimulate colonic epithelial proliferation 
and gastric epithelial differentiation, as well as does the C-terminally amidated gastrins (collectively, "the gastrins"); all of which are able to stimulate colonic proliferation, gastric epithelial proliferation and differentiation, and acid secretion [1].

Recently, numerous researchers have shown that the gastrins, specially including gly-G17 [2] and G17 [3], and progastrin all could promote tumorigenesis (e.g. gastric [4], colon [5], pancreatic [6] and non-small cell lung cancers [7]) in an autocrine, paracrine or endocrine manner [8-10], which has also warranted the gastrins as a preferred anti-tumor target in cancers expressing these stimulatory factors.

Gastric cancer is one of the most common malignant tumors in the world and second most frequent cause of cancer deaths, however more than $75 \%$ of patients present with gastric carcinomas that belong to advanced stages, and lose the opportunity for $\mathrm{cu}-$ rative surgery; leaving primarily chemotherapy as a major and important role in its treatment. At present, 5-Fluorouracil (5-FU) combined with cisplatin (CDDP) is a standard combined treatment in gastric carcinoma chemotherapy, however at this stage of disease its' efficiency and median survival time (MST) are just about $20 \%$, and 7 months respectively $[11,12]$. One of main reasons leading to a low efficiency is that the conventional drug combinations are highly cytotoxic, which often result in off-targeting-toxic effects (neutropenia, anemia, etc.) and may cause serious adverse reactions and unwanted side-effects (e.g. high grade emesis, emaciation and hypoimmunity). This is especially true for patients that have their tumors becoming increasingly resistant to the drugs and by simply increasing the dosage of chemotherapeutic drugs their adverse symptoms and quality of life, become increasingly more severe. Thus the need for novel combination treatments in antineoplastic therapy that would promote efficacious tumor reductions or even increased curative effects, and at the same time, also reduce or avoid serious adverse reactions, has got the attention of researchers and clinicians treating advanced gastric cancers.

With reference to the proliferative mechanism of the gastrins in promoting gastrin-stimulated tumors, this study elucidates the deployment of a novel vaccine combination, that is composed of the common $\mathrm{COOH}$-terminal amino acid sequences of progastrin, and the $\mathrm{NH}_{2}$-terminal amino acids of G17 and gly-G17 all covalently linked to Tetanus toxoid (TT) via peptide spacers, which induce the production of a spectrum of progastrin and gastrin neutralizing (anti-gastrins) antibodies, both the amidated and glycine extended forms, and thus reduces the availability of these growth factors to stimulated tumor proliferation. In addition we have also developed a combina- tion treatment, which has an additive action by using the anti-gastrins antiserum and a reduced amount of chemical drugs (5-FU + CDDP) in an anti-tumor protocol. Our research contents thus includes: a) the use of anti-gastrins vaccine that raises antibodies neutralizing G17, gly-G17, and progastrin, all growth proliferative species and b) the anti-gastrins antiserum combined with reduced cytotoxic drug combinations, (5-FU + CDDP) to inhibit the human gastric cancer cells, SGC7901 xenografted into nude mice.

\section{Materials and Methods}

\section{Cell line}

SGC7901 is a human gastri carcinoma cell-line. The cell-line was maintained in vitro in DMEM (GIBCO, US) supplemented with 5\% heat-inactivated fetal bovine serum (FBS) (GIBCO, US), 1\% penicillin-streptomycin and grown at $37^{\circ} \mathrm{C}$ in humidified conditions gassed with $5 \% \mathrm{CO}_{2}$.

\section{Immunogen}

The immunogen is composed of an equal mixture of the common carboxy-terminal progastrin amino acids and $\mathrm{NH}_{2}$-terminal amino acids of G17 and gly-G17 all covalently linked to Tetanus Toxoid (TT) by peptide spacers.

\section{Immunization procedure}

The vaccine $(0.25 \mathrm{mg} / \mathrm{kg})$ was injected i.m. into left or right leg of rabbits $(n=6)$. Rabbits were initially immunized using three injection at 2-week intervals. Control animals were normal rabbits that were used as a source for IgG sera.

\section{Anti-human G17gastrins antibody levels of vaccine-immunized rabbits $[13,14]$}

Rabbits were ear bled at time points throughout the experiment and at termination by cardiac puncture euthanization under terminal anaesthesia. Anti-human G17 antibody levels were determined by ELISA. $110 \mu \mathrm{l}$ per well of a $1 \mu \mathrm{g} / \mathrm{ml}$ solution of human G17-bovine serum albumin (BSA) conjugate (AoKe Corporation) in a coating buffer $\left(1.5 \mathrm{mg} / \mathrm{ml} \mathrm{Na}_{2} \mathrm{CO}_{3}\right.$, $3 \mathrm{mg} / \mathrm{ml} \mathrm{NaHCO}$, $\mathrm{pH}=9.6$ ) was coated into 96-well Immunulon U plates (Corning, USA) by an overnight incubation at $4^{\circ} \mathrm{C}$. The positive, negative and tested sera at 3.16-fold serial dilutions, starting at a dilution of 1:100, were prepared in antibody dilution buffer [phosphate buffer saline tween-20 (PBST), 1\% BSA]. Subsequent steps used the PBST $(8 \mathrm{mg} / \mathrm{ml} \mathrm{NaCl}, 3$ $\mathrm{mg} / \mathrm{ml} \mathrm{Na}{ }_{2} \mathrm{HPO}_{4} \cdot 12 \mathrm{H}_{2} \mathrm{O}, 2.5 \mathrm{mg} / \mathrm{ml} \mathrm{KCl}, 0.2 \mathrm{mg} / \mathrm{ml}$ $\mathrm{KH}_{2} \mathrm{PO}_{4}, 0.05 \%$ tween-20) without BSA was used for washings. The 96-well plates were washed $4 \mathrm{X}$ to free of non-bound conjugates, then the sera were added (100 $\mathrm{\mu l} /$ well). After 1.5 hour inbubation at room 
temperature (RT), the plates were washed four times and a goat anti-rabbit IgG $(\mathrm{H}+\mathrm{L})$ alkaline phosphatase conjugate was added (1:1000 dilution in antibody dilution buffer, $100 \mu \mathrm{l} /$ well). After 1.5 hour inbubation at RT, the plates were washed four times to remove nonbound reagent, and $100 \mu \mathrm{l} /$ well of pNPP substrate solution $(1 \mathrm{mg} / \mathrm{ml})$ was added in substrate buffer $\left(0.01 \mathrm{mg} / \mathrm{ml} \mathrm{MgCl} 2 \cdot \mathrm{H}_{2} \mathrm{O}, 10 \%\right.$ diethanolamine). After $5 \mathrm{~min}$ incubation in dark at RT, $100 \mu \mathrm{l} /$ well of stop buffer $(1.0 \mathrm{M} \mathrm{NaOH})$ was added and absorbance was measured on a microplate reader $405_{\mathrm{nm}}$ (reading wave) $/ 490_{\mathrm{nm}}$ (reference wave). The values of $490_{\mathrm{nm}}$ were subtracted from that of $405 \mathrm{~nm}$, and the antibody titer was calculated by using $\mathrm{ED}_{50}$ ( $50 \%$ effective dose) module of SCANLT software.

\section{Specificity of antibodies raised in rabbits against anti-gastrin vaccine $[13,15]$}

A competitive ELISA was used to assess the specificity of the affinity of antibodies for G17 peptide. A fixed concentration of antiserum (1:50 dilution) was combined with the same volume of various inhibitors at 10-fold serial dilutions and incubated for 1 hour at room temperature. Then taking the mixture as primary antibody, other procedures were the same as the ELISA in detecting antihuman G17 antibody levels of vaccine-immunized rabbits. The inhibitors included E. coli expressed his-tagged Progastrin, G17, gly-G17, G34, vasoactive intestinal peptide (VIP), TT, and buffer (no inhibitor). Samples were run in quadruplicate, and means were calculated for each concentration. The \% Inhibition relative to no inhibitor added (antiserum + buffer) was calculated for each inhibitor tested: \%Inhibition $=100 \%\left(\mathrm{~A}_{\text {uninhibited }}-\mathrm{A}_{\text {inhib- }}\right.$ ited) / $\mathrm{A}_{\text {uninhibited, where } \mathrm{A}=\text { Absorbance. }}$

\section{Establishment of carcinoma models}

Semi-confluent cell monolayers were harvested with $0.25 \%$ trypsin-EDTA. Confluent cell monolayers were washed twice and suspened in sterile PBS at a concentration of $1.0 \times 10^{7}$ cells $/ \mathrm{ml}$ in an ice-bath. A 0.45 $\mathrm{ml}$ volume was then injected into female nude mice (6-8 weeks old, weighting 17-20 g) subcutaneously on the back. The tumor pieces $\left(3-5 \mathrm{~mm}^{3}\right.$ in saline) were implanted into animals subcutaneously on the back. The mice were maintained in sterile isolation, fed and watered ad libitum. When tumors grew to $100 \mathrm{~mm}^{3}$, the mice were grouped to distribute and equalize tumor volumes.

\section{Treatments}

After being distributed into seven groups: a 5-FU at $50 \mathrm{mg} / \mathrm{kg}$ was combined with CDDP at $5 \mathrm{mg} / \mathrm{kg}$ as standard high-dose chemotherapeutic combination group (H.C.) that was administered i.p. every 10 days, and a normal rabbit (gastrin-negative IgG containing) serum at $200 \mathrm{mg} / \mathrm{kg}$ as a negative control (N.C.), which was administered i.p. every 2 days. Other groups consisted of: the anti-gastrins antiserum at doses of $200 \mathrm{mg} / \mathrm{kg}, 150 \mathrm{mg} / \mathrm{kg}$, and $100 \mathrm{mg} / \mathrm{kg}$ (indicated as combined high dose $(\mathrm{H})$; combined medium dose $(\mathrm{M})$, and combined low dose (L) groups respectively). Each of the groups were administered respective sera, i.p. every 2 days that was all combined with 5-FU at the $40 \%$ lower chemotherapeutic dosages of $20 \mathrm{mg} / \mathrm{kg}$ and CDDP at $2 \mathrm{mg} / \mathrm{kg}$ administered i.p. every 7 days. The anti-gastrins antiserum alone was at $200 \mathrm{mg} / \mathrm{kg}$ given as a singular antiserum group that was administered i.p. every 2 days, while chemotherapy group of 5-FU at $20 \mathrm{mg} / \mathrm{kg}$ combined with CDDP at $2 \mathrm{mg} / \mathrm{kg}$ was given as a singular chemical combination for this group, and was administered i.p. every 7 days. Each experimental group was composed of 8 animals.

Animals were inspected daily and weighed every 2 days. Tumor volumes were measured twice weekly in a blind manner by an independent observer. The measurement was performed 3 times daily; measurements were taken and the mean of the 3 measurements at each time point was recorded. The mice were treated for a period of 26 days, sacrificed and the tumors removed for study. The weight, volume of tumors and weight of body were also carried out by an independent observer who was blind to the treatment groups. Means and standard deviation of the means were calculated for each group (means \pm $\mathrm{SD})$.

\section{Histological evaluation of the SGC-7901 tu- mors}

Tumor specimens were $4 \%$ formalin-fixed. Sections were then embedded in paraffin, $4-5 \mu \mathrm{m}$ sections were cut by a microtome and stained with haematoxylin and eosin (HE). Assessment of tumour necrosis area was made by a histopathologist in a blind manner by image analysis.

\section{Statistical analysis}

All experiments were repeated three times. The data were analyzed between groups using Student's $t$ test. $p$ values $<0.05$ were considered statistically significant.

\section{Results}

\section{Human Anti-Gastrin 17 Antibody Levels of Vaccine-immunized Rabbits}

Six rabbits were immunized with the immunogen vaccine and their antibody titers followed for a period of 8 weeks following three immunizations. Fig. 1 shows the antibody levels against G17 as assessed by the described ELISA technique. Following three 
immunizations, antibodies were detectable by week 4 in all rabbits. The initial surge of antibodies by week 4 was followed by a second surge by week 6 (p $<0.05$ vs week 4), after which the antibody titers declined and approached the level of week 4 by week 8 ( $p>0.05$ vs week 4) (Fig. 1).

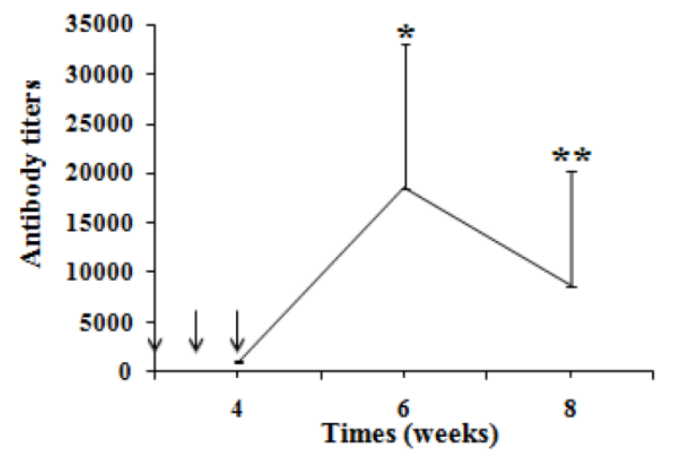

Figure 1. Time scale of antibody titers of rabbits immunized by vaccine $(0.25 \mathrm{mg} / \mathrm{kg})$ at the time points shown. Each point represents mean antibody titers $(n=6)$. Antibody titers were measured by an ELISA assay using a 1:100 dilution of antisera. Immunizations are indicated by arrows, ${ }^{*} \mathrm{p}<0.05$ vs 4 weeks, **p $>0.05$ vs 4 weeks.

Normal rabbits were selected as negative control in the study, of which the protein concentration was equal to that of antiserum, but the G17 antibody titers was undetectable.

During the period of immunization, there was no local or systemic reactions induced (e.g. swelling, or festering) in the injection site of rabbits. The weight, which significantly increased $(\mathrm{p}<0.05$, data not shown) at termination, their appetites and other clinical features of the rabbits also showed no abnormalities. Besides using the dose of $0.25 \mathrm{mg} / \mathrm{kg}$, another two doses including $0.125 \mathrm{mg} / \mathrm{kg}$ and $0.5 \mathrm{mg} / \mathrm{kg}$ immunogen have been studied. However the antibody titers for the $0.125 \mathrm{mg} / \mathrm{kg}$ dose was deemed too low, whereas the dose of $0.5 \mathrm{mg} / \mathrm{kg}$ had some serious local tissue reactive responses, and was therefore not used, even though there were high levels of antibody (data not shown).

The antiserum used to inhibit human gastric cancer SGC7901 cell growth in nude mice was prepared from the blood collected at week 6 by the optimal immunization program adopted in this study. Animals received three immunization injections initially and, a booster immunization would be administered if anti-gastrin antisera levels declined by more than $60 \%$ over the experimental times.

\section{Gastrin specificity of antiserum raised by vac- cine immunization of rabbits}

Fig. 2 presents the percent inhibition of antibodies binding to G17-BSA as a function of inhibitor concentration. As can be seen in the figure, G17 and
gly-G17 significantly inhibited antibodies binding to G17-BSA with their concentrations increasing ( $p<$ 0.05). Approximately $80 \%$ inhibition was attained with the G17 and gly-G17, however no inhibition was obtained by using TT, G34 and VIP. The $\mathrm{NH}_{2}$-terminals of G17 and gly-G17 was the same with the shared peptides epitope of immunogen vaccine, and so the results suggest that the affinity of antibody in antiserum was specific for binding the G17 and gly-extended G17 peptides.

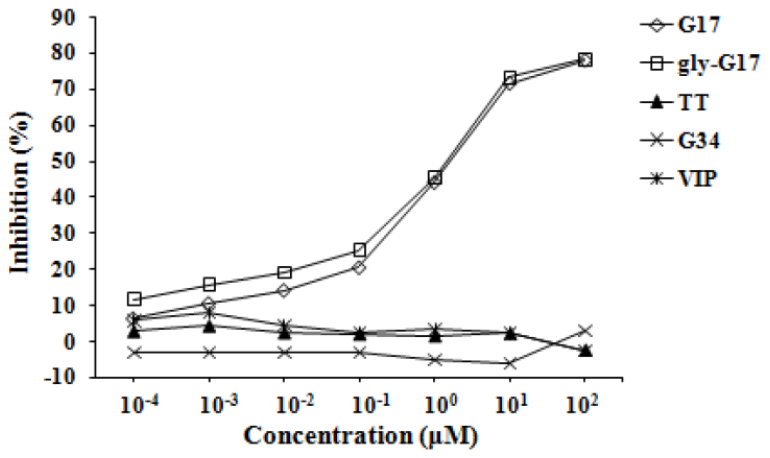

Figure 2. Inhibition of anti-G17 antibodies binding to G17-BSA by peptide competitive inhibitors. G17-BSA were absorbed onto a solid phase, inhibition was determined in a competive ELISA with a fixed concentration of antiserum (1:50 dilution) combined with serial dilutions $\left(10-4-10^{2} \mu \mathrm{M}\right)$ of competitive inhibitors. $\%$ Inhibition $=100 \%\left(A_{\text {uninhibited }}-A_{\text {inhibited }}\right) / A_{\text {uninhibited, }}$ where $A=$ Absorbance.

Inhibition of antibodies binding to progastrin C-terminal peptide-bound to BSA was also effected and was a function of inhibitor concentration, using progastrin-specific peptides and trypsin digests of his-tagged (Ni-NTA column purified) expressed progastrin (data not shown).

TT was the carrier protein of vaccine, which could be recognized by antigen presenting cells and presented to $\mathrm{CD}^{+} \mathrm{Th}$ cells. Th cells then provied the second signal needed in B cells activation, which could exert immunological enhancement and promote production of a high levels of neutralizing antibodies. The results indicated that TT also could did not interfere in the role of binding of gastrins to immunogen-induced antibodies.

G34 and VIP were two types of gastrointestinal hormones, which were neuropeptides distributed at low levels, but widely distributed throughout the gastrointestinal tract, and central and peripheral nervous systems, having various biological activities, and were important in maintaining the normal physiological status and function of body. G34 could promote acid secretion and gastrointestinal mucous membrane proliferation, VIP could regulate blood pressure, boost myocardial contractility and dialatevessels. Anycross reactivity between those hormones and the immunogen induced antibodies could pre- 
dictively produce untoward effects of the immunogen induced antibodies; however the results indicate that there were no non-specific interferences occurring between them.

A

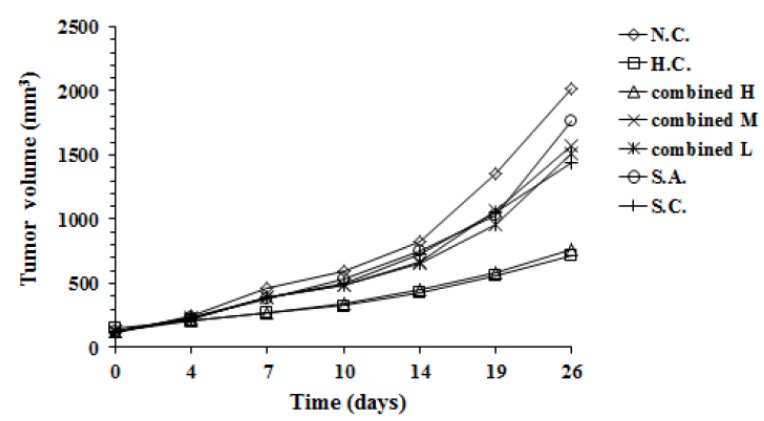

B

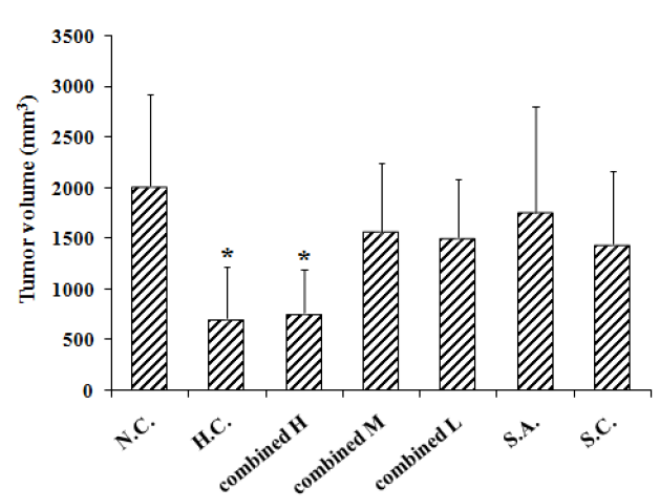

C

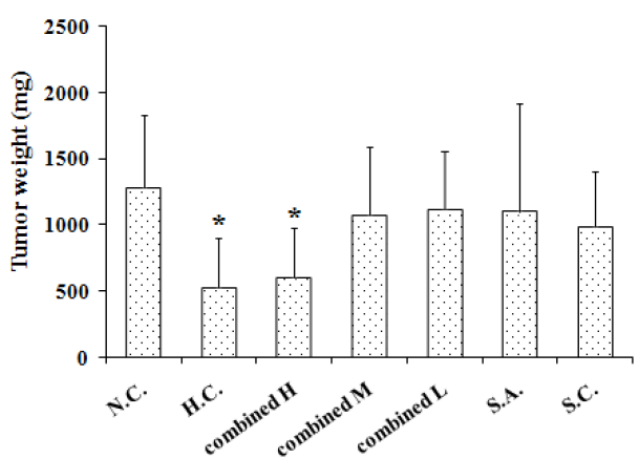

Figure 3. A combination of anti-gastrins antiserum and cytotoxic drugs (5-FU + CDDP) treatment assessed on the growth curve (A), the final median volume (B), the final median weight (C) of SGC-7901 tumors. (a) diamond, N.C. ( $\diamond$ negative control), normal rabbit serum $(200 \mathrm{mg} / \mathrm{kg} / 2$ days, i.p.) treated; square, H.C. ( $\square$ standard high-dose chemotherapeutic combination), 5-FU (50 $\mathrm{mg} / \mathrm{kg} / 10$ days, i.p.) combined with $\operatorname{CDDP}(5 \mathrm{mg} / \mathrm{kg} / 10$ days, i.p.) treated; triangle, combined $\mathrm{H}$ ( $\Delta$ combined high dose), antiserum $(200 \mathrm{mg} / \mathrm{kg} / 2$ days, i.p.) combined with lowered ( $40 \%$ reduced) $5-\mathrm{FU}(20 \mathrm{mg} / \mathrm{kg} / 7$ days, i.p.) and CDDP $(2 \mathrm{mg} / \mathrm{kg} / 7$ days, i.p.) treated; cross, combined $\mathrm{M}$ ( $\times$ combined medium dose), antiserum $(150 \mathrm{mg} / \mathrm{kg} / 2$ days, i.p.) combined with 5 -FU $(20 \mathrm{mg} / \mathrm{kg} / 7$ days, i.p.) and CDDP $(2 \mathrm{mg} / \mathrm{kg} / 7$ days, i.p.) treated; crossed star, combined $\mathrm{L}$ ( $*$ combined low dose), antiserum (100 mg/kg/2 days, i.p.) combined with $5-\mathrm{FU}(20 \mathrm{mg} / \mathrm{kg} / 7$ days, i.p.) and CDDP ( $2 \mathrm{mg} / \mathrm{kg} / 7$ days, i.p.) treated; circle, S.A. (o single antiserum), antiserum ( $200 \mathrm{mg} / \mathrm{kg} / 2$ days, i.p.) treated; line, S.C. (+ single chemical), $40 \%$ reduced 5 -FU ( $20 \mathrm{mg} / \mathrm{kg} / 7$ days, i.p.) combined with $40 \%$ reduced CDDP ( 2 $\mathrm{mg} / \mathrm{kg} / 7$ days, i.p.) treated. Experimental groups consisted of 8 animals. The data were analyzed between groups using Student's $t$ test. Statistical significance: *p < 0.05 vs N.C.
In vivo analysis of the therapeutic effect of anti-gastrins antiserum in combination with low dosage chemical drugs (5-FU + CDDP) on human SGC-7901 gastric tumors

Fig. 3A, 3B and $3 \mathrm{C}$ show the effect of anti-gastrins antiserum in combination with cytotoxic drugs on the growth curve, final volume and weight of SGC-7901 tumors respectively. As shown in Fig.3A, the tumor growth trend of the standard high-dose chemotherapeutic combination (H.C.) corresponded to that of combined high dose $(\mathrm{H})$ antibody group with the lower levels of 5FU + CDDP. Similarly median volumes (Fig. 3B) of tumors from standard high-dose chemotherapeutic combination (H.C.) and the combined high dose antibody and lower-dose chemo $(\mathrm{H})$ groups, had no significant difference $(\mathrm{p}=$ $0.8089)$ with one another; each were reduced by $65 \%$ $(p=0.0016)$, and $62 \%(p=0.0017)$ respectively when compared to antibody negative controls (N.C.). The volumes of combined medium dose $(\mathrm{M})$, combined low dose (L), single antibody (S.A.) and low dosage single chemical (S.C.) groups were not significantly different from that of negative controls (N.C.) group ( $p=0.1391,0.1008,0.3010,0.0894$, respectively).

Median weights (Fig. 3C) of tumors from standard high-dose chemotherapeutic combination treated (H.C.) and combined high dose antibody $(\mathrm{H})$ groups, showed no significant differences $(p=0.6859)$ between each other, and were reduced by $59 \%(\mathrm{p}=$ $0.0033)$, and $53 \%(\mathrm{p}=0.0062)$ respectively when compared to negative controls (N.C.). The weights of the combined medium (M), combined low dose (L), single antibody (S.A.) and sole chemotherapies (S.C.) groups were also not significantly different from that of negative control(N.C.) group ( $p=0.2324,0.2642$, $0.3114,0.1270$, respectively).

Table 1 shows the \%RTP of H.C. and combined $H$ groups are $22 \%(p=0.0001), 28 \%(p=0.0018)$ respectively, the \%TWI of H.C. and combined $\mathrm{H}$ groups are $59 \%(p=0.0033), 53 \%(p=0.0062)$ respectively. The results indicated that treatment with a combination of anti-gastrins antiserum and lowered doses of cytotoxic drugs could achieve the optimal therapeutic effect as that of using a high dose of cytotoxic drugs with respect to inhibiting the growth of the human SGC-7901 gastric cancer tumors.

The antiserum and chemical drugs used in combined $\mathrm{H}$ group were separated to form the S.A. and S.C. groups respectively to study the interrelation between them after the combined using. As shown in RTV, S.C., whose dose was equal to the $40 \%$ dose of H.C., had weak anti-tumor effect, S.A. had no anti-tumor effect, however combining application of them to form the combined $\mathrm{H}$ group could produce synergy anti-tumor effect. The results suggested that 
the anti-gastrins sera could increase the sensitivity of the tumors to chemotherapeutic drugs. We inferred that besides promoting tumor proliferation, invasion, metastasis and anti-apoptosis, the gastrins as growth factors might also enhance the multi-drug resistance (MDR) of tumor, but whose mechanisms needed to be studied further in detail.

Table 1. The relative tumor proliferation and tumor weight inhibition of treatment groups

\begin{tabular}{|c|c|c|c|}
\hline $\begin{array}{l}\text { Groups } \\
(\mathrm{n}=8)\end{array}$ & $\begin{array}{l}\text { Relative tumor } \\
\text { volumes } \\
(\text { Mean } \pm \mathrm{SD})\end{array}$ & $\begin{array}{l}\text { Relative tumor } \\
\text { proliferation } \\
(\%)\end{array}$ & $\begin{array}{l}\text { Tumor weight } \\
\text { inhibition } \\
(\%)\end{array}$ \\
\hline N.C. & $22.29 \pm 10.85$ & / & / \\
\hline H.C. & $\underline{4.90 \pm 3.49^{* *}}$ & $22(<40)$ & $\underline{59(>30)}$ \\
\hline Combined H & $\underline{6.16 \pm 2.65^{* *}}$ & $\underline{28}(<40)$ & $\underline{53(>30)}$ \\
\hline Combined M & $14.73 \pm 5.25^{*}$ & 66 & 16 \\
\hline Combined L & $13.24 \pm 4.49^{*}$ & 59 & 13 \\
\hline S.A. & $15.78 \pm 8.79$ & 71 & 14 \\
\hline S.C. & $12.72 \pm 4.89^{*}$ & 57 & 23 \\
\hline \multicolumn{4}{|c|}{ 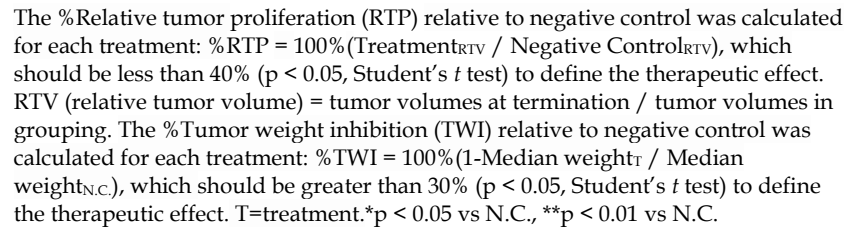 } \\
\hline
\end{tabular}

Fig. 4A and Fig. 4B show the body weight changes and the final median body weight of all groups during the experiment, respectively. Over the duration of the experimental period, the body weights of standard high-dose chemotherapeutic combination (H.C.) had a significant decline $(\mathrm{p}<0.05)$ compared to that of the other groups. The standard high-dose chemotherapeutic combination group animals had body weights significantly reduced by $20 \%$ (p = 0.0006 ) compared to those in other groups; moreover, animals in the standard high-dose chemotherapeutic combination group (H.C.) also exhibited diarrhea after each high dose administration. Further the weights of other groups showed no significant differences among themselves, unlike the high dosage positive controls $(p>0.05)$. Additionally all animals given low dosage chemotherapeutics, or just antisera alone, showed no abnormal clinical reactions, unlike standard high-dose chemotherapeutic combination given the higher dosages of chemotherapeutic drugs.

The weights of standard high-dose chemotherapeutic combination treated animals (H.C.) were reduced by $17 \%(p=0.0035)$ compared to the weights of the negative controls (N.C.) at termination. The other groups had no significant difference when compared to the negative controls ( $p>0.05$ vs N.C.). These findings suggest that the standard (higher) doses of the chemotherapeutic drugs used in standard high-dose chemotherapeutic combination (H.C.) have significantly stronger toxicities and side effects; whereas the antiserum had no such effects.

$\mathbf{A}$
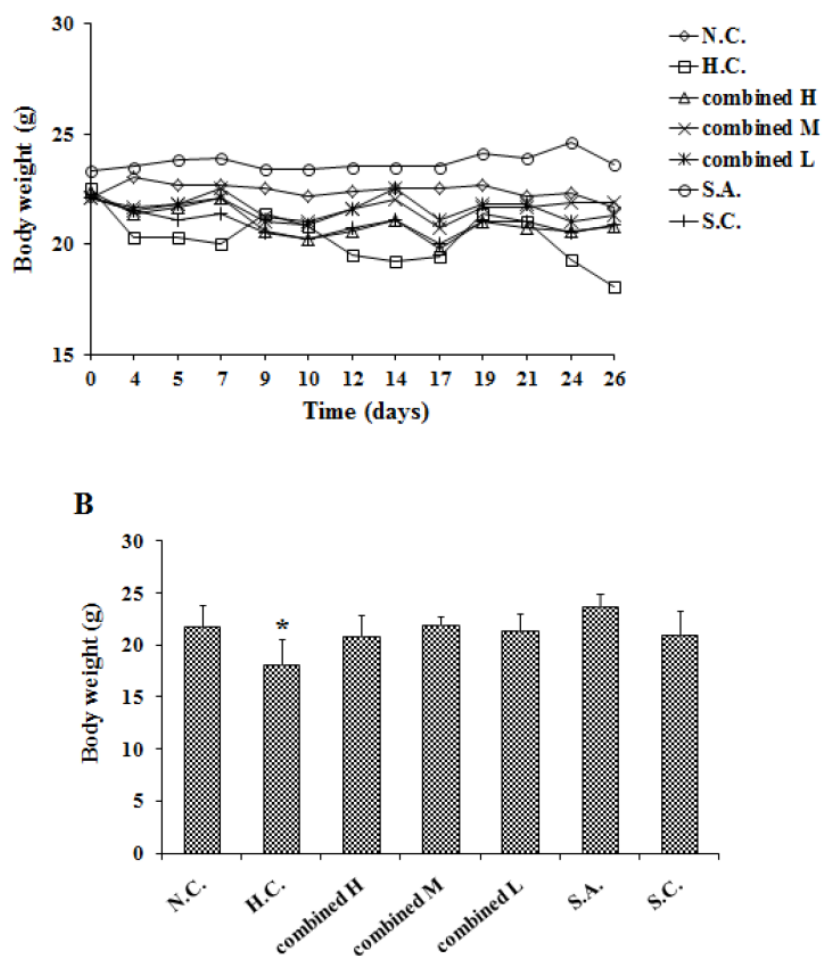

Figure 4. A combination of anti-gastrins antiserum and cytotoxic drugs (5-FU $+C D D P)$ treatment assessed on the body weight changes $(A)$ and the effects on final median body weight (B).* ${ }^{*}<0.05$ vs N.C. $(n=8)$

\section{Histological evaluation of SGC7901 tumors}

Table 2 shows the mean scores of N.C., H.C. and combined $\mathrm{H}$ groups graded for necrosis; samples were $0.875,2.625,2.25$ respectively, which indicate the extent of pathology and degree of necrosis. The degree of standard high-dose chemotherapeutic combination (H.C.) necrosis corresponded to that of the combined high dose $(\mathrm{H})$ group and also revealed that the tumors from animals treated with high chemotherapeutics (H.C. and combined $\mathrm{H}$ ) groups sustained a greater degree of necrosis (Fig. 5B, Fig. 5C) when compared to tumors from negative controls (N.C.) (Fig. 5A).

Table 2. Pathology necrosis graded scores stained with HE

\begin{tabular}{llllll}
\hline \multirow{2}{*}{$\begin{array}{l}\text { Groups } \\
(\mathrm{n}=8)\end{array}$} & \multicolumn{3}{l}{ Numbers with different levels of necrosis } & \multirow{2}{*}{$\begin{array}{l}\text { Mean } \\
\text { seores }\end{array}$} \\
\cline { 2 - 5 } & 0 points & 1points & 2 points & 3 points & \\
\cline { 2 - 5 } & $(<25 \%)$ & $(25 \% \sim 50 \%)$ & $(50 \% \sim 75 \%)$ & $(>75 \%)$ & \\
\hline N.C. & 2 & 5 & 1 & $/$ & 0.875 \\
H.C & $/$ & $/$ & 3 & 5 & 2.625 \\
Combined H & $/$ & 2 & 2 & 4 & 2.25 \\
\hline
\end{tabular}




\section{A}

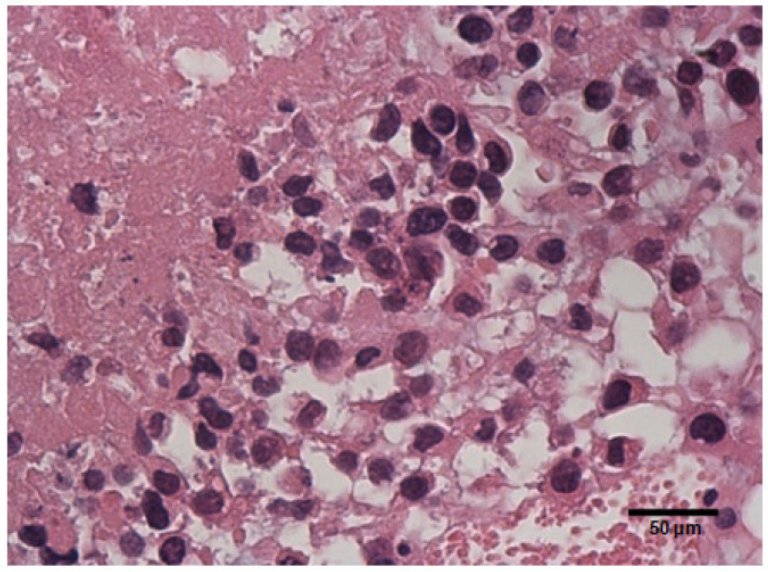

B
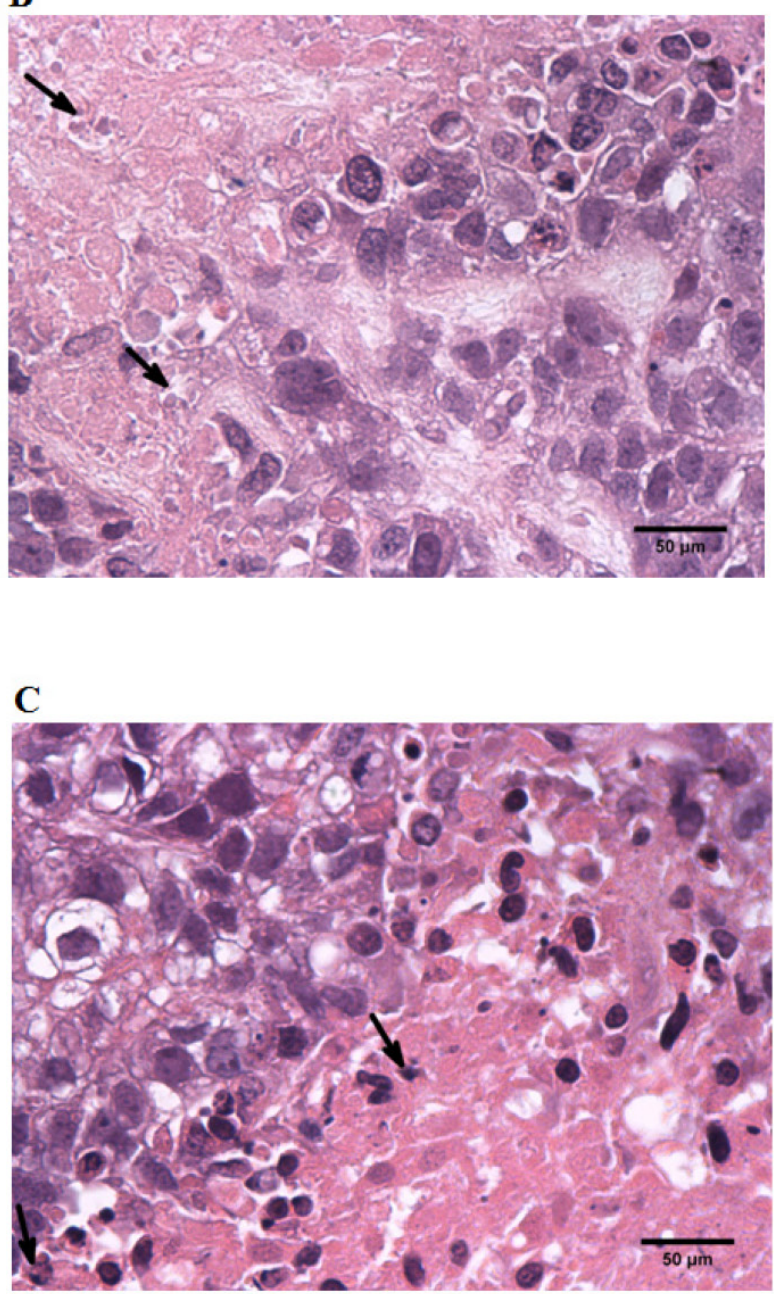

Figure 5. Histology of SGC-7901 tumor from SCID mice. A, A section from tumor-cells of animals treated with negative control sera (N.C.) $\times 40$. B, A section from tumor-cells of animals treated with standard high-dose chemotherapeutic combination protocols (H.C.) $\times 40$. C, A section from tumor-cells of animals treated with combined-high dosage $(\mathrm{H})$ group protocols $\times 40$. All tumors were formalin fixed, paraffin embedded, and stained with hematoxylin and eosin. All assessments were made "blind" by an independent pathologist.

\section{Discussion}

The action mechanism of gastrins conforms to the signal-receptor theory that gastrins as ligands combine with their cognate receptors to stimulate relevant signaling pathways and thus exert pro-proliferative biological effects. The gastrins mainly stimulate cholecystokinin (CCK) family receptors (e.g. CCK-A, CCK-B or "classical" receptors) [16]; however there are also a number of potential "non-classical" receptors that have been reported to bind gastrins, especially the pro-gastrin species [17]. Many signal pathways (e.g. PKC [18], ERK/MAPK [19], PI3K/Ak [20], P125-FAK [21], JAK/STAT [22] signals) can be activated through the "classical" CCK receptors by the gastrins, which involve many of the known signal transduction pathways and share extensive signaling cross relationships [23]. Thus there is a strong body of information showing that the gastrins are able to produce many pro-malignant biological effects including promoting tumor proliferation [24], invasion [25], metastasis [26] and anti-apoptosis [27].

Currently there are mainly three kinds of methods aimed at targeting, primarily, gastrin 17 to effect an anti-tumor response, by inhibiting the secretion of this gastrin hormone (e.g. somatostatin [28], iRNA [29]), receptor antagonists (e.g. L-364718, L-365260, YM-022) [30] and by immunization to neutralize gastrin 17 (e.g. monoclonal antibody, vaccines [31]). A number of high affinity CCK-A and CCK-B receptor antagonists $[32,33]$ have been exploited to inhibit the proliferative effects of gastrin-17, however they lacked specificity as they also blocked the actions of all the potential ligands of these receptors, such as G34 and CCK, meanwhile the receptors in tumors also were seen to undergo mutations and thus became insensitive to this receptor approach and therefore they could not block the potential proliferative activity of the hormone and its precursors that were being bound by non-classical receptor proteins that were also involved in tumor growth [30]. The use of somatostatin also lacked specificity and its use might upset the normal role of other hormones in the body. Monoclonal antibodies against receptors might have had positive effects, but not on mutated receptors, and long-term usage introduces immunogenicity and infusion-related reactions and is extremely expensive to be widely used in so frequent a cancer as gastric cancer is in Asia. The immunogen-vaccine designed to neutralize gastrins would overcome many of these shortcomings both in theory and in practice, which has become the research focus of this study.

This novel immunogen-vaccine in the presented study, a conjugated Gastrins-TT, consists of three parts, and includes the common amino-terminal por- 
tion of human G17 and gly-G17and the carboxy-terminal portion of progastrins as antigenic epitopes, covalently attached to peptide spacers orienting the epitopes to B cells recognition, all covalently attached to tetanus toxoid (TT) as the carrier protein to enhance the immunization process. As seen in the present study, the ELISA demonstrated the specificity of antibodies rasied by the vaccine. The results of G17, gly-G17 and G34 observed in the present study correlated well with those reported by others [13] who showed by using ELISA that there was a similar specificity to that of their $\mathrm{NH}_{2}$-terminal specific immunogen without any interference or inhibition by other GI-related peptide hormones.

More interestingly and clinically more relevant, is our studies using the gastric cancer along with clinical standard chemotherapeutic treatment that is a combination of 5-FU and CDDP but at a reduced $(40 \%)$ level of standard dosage, in combination with our anti-human gastrins antisera and comparing it to the clinical standard cytotoxic combination treatment at the usual (higher dosages). By comparing the clinical indicators including tumor volumes / weights, relative tumor proliferation (RTP), tumor weight index (TWI) as well as levels of associated necrosis of the treatments, both protocols were essentially equivalently effective at reducing tumor growth, except the deployment of antisera in combination with reduced chemotherapeutic drugs considerably reduced adverse side effects as measured by clinical determinants such as body weight and tissue necrosis. Interestingly, we found the additive anti-tumor effect between anti-gastrin antisera and chemotherapeutic drugs are perhaps due in part to the multiplicity of activating roles that the gastrins are known to have on the proliferation of GI cancers; and so by inhibiting these growth factors, weaken tumor cells, making lower dosages of chemotherapeutics more effective. The precise mechanisms, individually, however will have to be examined and explored in detail.

The characterization of gastrin dependence of the SGC7901 cells had been undertaken with respect to gastrin-associated proliferative parameters by Jian Jiang Zhouet al. (2010) [34], who showed by RT-PCR the presence of gastrin and CCK-B receptor associated with SGC-7901 cells that these cells not only coexpressed gastrin and CCK-B receptor mRNAs, but also endogenously secreted gastrin protein into the culture medium, thus forming a gastrin-CCK-B receptor autocrine loop. They also reported that disrupting the gastrin-CCK-B receptor autocrine loop by neutralizing the endogenous gastrin or by knocking down CCK-B receptor expression, they could significantly inhibit cell proliferation and decreased the percentage of cells residing in the S-phase of the cell cycle, but could not demonstrate the precise roles of various gastrins.

Significant inhibtion of in vitro growth was not shown with the anti-gastrin antiserum alone (data not shown), in these cells, which might be possibly due to the proliferation effect of the nutritional content that is associated with the crude antisera, and would necessitate the use of affinity purified anti-sera to perhaps demonstrate the inhibiting effect of higher amounts of anti-human gastrin antibodies.

In conclusion, this work indicated that the beneficial therapeutic effect of combined low dosage cytotoxic chemotherapy with anti-human gastrin antisera, which was as effective at inhibiting the gastric cancer xenograft tumor proliferation of higher dosage chemotherapy, but with lessened toxic side-effects. Such studies would warrant further combination studies with lower dose chemotherapeutics, along with anti-gastrin sera on gastrin responsive GI tumors, and might signify new clinically important protocols for their combined use in the future treatments of gastric and other GI cancers.

\section{Acknowledgements}

We acknowledge Jian Luo, Ganhua You, Yuan Zhang and Yanlin $\mathrm{Wu}$ for their invaluable technical assistance.

\section{Competing Interests}

The authors have declared that no competing interest exists.

\section{References}

1. Dockray GJ, Varro A, Dimaline R, et al. The gastrins: their production and biological activities. Annu Rev Physiol. 2001; 63: 119-139.

2. Stepan VM, Sawada M, Todisco A, et al. Glycine-extended gastrin exerts growth-promoting effects on human colon cancer cells. Mol Med.1999; 5(3): 147-159.

3. Ferrand A, Wang TC. Gastrin and cancer: A review. Cancer Lett. 2006; 238(1): $15-29$.

4. Burkitt MD, Varro A, Pritchard DM. Importance of gastrin in the pathogenesis and treatment of gastric tumors. World J Gastroenterol. 2009; 15(1): 1-16.

5. Watson SA, Morris TM, McWilliams DF, et al. Potential role of endocrine gastrin in the colonic adenoma carcinoma sequence. Br J Cancer. 2002; 87(5): 567-573.

6. Harris JC, Gilliam AD, McKenzie AJ, et al. The biological and therapeutic importance of gastrin gene expression in pancreatic adenocarcinomas. Cancer Res. 2004; 64(16): 5624-5631.

7. Sethi T, Herget $\mathrm{T}, \mathrm{Wu} \mathrm{SV}$, et al. CCKA and CCKB receptors are expressed in small cell lung cancer lines and mediate $\mathrm{Ca} 2+$ mobilization and clonal growth. Cancer Res. 1993; 53(21): 5208-5213.

8. Watson SA, Morris TM, Varro A, et al. A comparison of the therapeutic effectiveness of gastrin neutralization in two human gastric cancer models: relation to endocrine and autocrine/paracrine gastrin mediated growth. Gut. 1999; 45(6): 812-817

9. Noble PJ, Wilde G, White MR, et al. Stimulation of gastrin-CCKB receptor promotes migration of gastric AGS cells via multiple paracrine pathways. Am J Physiol Gastrointest Liver Physiol. 2003; 284(1): G75-84.

10. Kovac S, Xiao L, Shulkes A, et al. Gastrin increases its own synthesis in gastrointestinal cancer cells via the CCK2 receptor. FEBS Lett. 2010; 584(21): 4413-4418

11. Vanhoefer U, Rougier P, Wilke H, et al. Final results of a randomized phase III trial of sequential high-dose methotrexate, fluorouracil, and doxorubicin versus etoposide, leucovorin, and fluorouracil versus infusional fluorouracil and cisplatin in advanced gastric cancer: A trial of the European Organization for Research and Treatment of Cancer Gastrointestinal Tract Cancer Cooperative Group. J Clin Oncol. 2000; 18(14): 2648-2657. 
12. Ohtsu A, Shimada Y, Shirao K, et al. Randomized phase III trial of fluorouracil alone versus fluorouracil plus cisplatin versus uracil and tegafur plus mitomycin in patients with unresectable, advanced gastric cancer: The Japan Clinical Oncology Group Study (JCOG9205). J Clin Oncol. 2003; 21(1): 54-59.

13. Watson SA, Michaeli D, Grimes S, et al. Gastrimmune raises antibodies that neutralize amidated and glycine-extended gastrin-17 and inhibit the growth of colon cancer. Cancer Res. 1996; 56(4): 880-885.

14. Watson SA, Michael D, Justin TA, et al. Pre-clinical evaluation of the gastrimmune immunogen alone and in combination with 5-fluorouracil/leucovorin in rat colorectal cancer model. Int J Cancer. 1998; 75(6):873-877.

15. Michaeli D, Caplin M, Watson SA, et al. Immunogenic compositions to the CCK-B/gastrin receptor and methods for the treatment of tumors. Patent Application Publication, 1998; PCT/US1998/009957.

16. Rozengurt E, Walsh JH. Gastrin, CCK, signaling, and cancer. Annu Rev Physiol. 2001; 63: 49-76.

17. Singh P. Role of Annexin-II in GI cancers: interaction with gastrins/progastrins. Cancer Lett. 2007; 252(1): 19-35.

18. Ogasa M, Miyazaki $Y$, Hiraoka S, et al. Gastrin activates nuclear factor kappaB (NFkappaB) through a protein kinase $\mathrm{C}$ dependent pathway involving NfkappaB inducing kinase, inhibitor kappaB (IkappaB) kinase, and tumournecrosis factor receptor associated factor 6 (TRAF6) in MKN-28 cells transfected with gastrin receptor. Gut. 2003; 52(6): 813-819.

19. Song LJ, Liu RJ, Zeng Z, et al. Gastrin inhibits a novel, pathological colon cancer signaling pathway involving EGR1, AE2, and P-ERK. J Mol Med (Berl). 2012; 90(6): 707-718.

20. Hollande F, Choquet A, Blanc EM, et al. Involvement of phosphatidylinositol 3-kinase and mitogen-activated protein kinases in glycine-extended gastrin-induced dissociation and migration of gastric epithelial cells. J Biol Chem. 2001; 276(44): 40402-40410.

21. Daulhac L, Kowalski-Chauvel A, Pradayrol L et al Gastrin stimulates the formation of a p60Src/p125FAK complex upstream of the phosphatidylinositol 3-kinase signaling pathway. FEBS Lett. 1999; 445(2-3): 251-255.

22. Ferrand A, Kowalski-Chauvel A, Bertrand C, et al. Involvement of JAK2 upstream of the PI 3-kinase in cell-cell adhesion regulation by gastrin. Exp Cell Res. 2004; 301(2): 128-138.

23. Yassin RR. Signaling pathways mediating gastrin's growth promoting effects. Peptides. 1999; 20(7): 885-898.

24. Pradeep A, Sharma C, Sathyanarayana P, et al. Gastrin-mediated activation of cyclin D1 transcription involves beta-catenin and CREB pathways in gastric cancer cells. Oncogene. 2004; 23(20): 3689-3699.

25. Baba M, Itoh K, Tatsuta M. Glycine-extended gastrin induces matrix metalloproteinase-1- and -3-mediated invasion of human colon cancer cells through type I collagen gel and Matrigel. Int J Cancer. 2004; 111(1): 23-31.

26. Hollande F, Choquet A, Blanc EM, et al. Involvement of phosphatidylinositol 3-kinase and mitogen-activated protein kinases in glycine-extended gastrin-induced dissociation and migration of gastric epithelial cells. J Biol Chem. 2001; 276(44): 40402-40410.

27. Müerköster S, Isberner A, Arlt A, et al. Gastrin suppresses growth of CCK2 receptor expressing colon cancer cells by inducing apoptosis in vitro and in vivo. Gastroenterology. 2005; 129(3): 952-968.

28. Watson SA, Durrant LG, Morris DL. The effect of the E2 prostaglandin enprostil, and the somatostatin analogue SMS 201995 , on the growth of a human gastric cell line, MKN45G. Int J Cancer. 1990; 45(1): 90-94.

29. Grabowska AM, Hughes J, Watson SA. Use of interfering RNA to investigate the role of endogenous gastrin in the survival of gastrointestinal cancer cells. Br J Cancer. 2007; 96(3): 464-473.

30. Dufresne M, Seva C, Fourmy D. Cholecystokinin and Gastrin Receptors. Physiol Rev. 2006; 86(3): 805-847.

31. Gilliam AD, Watson SA. G17DT: an antigastrin immunogen for the treatment of gastrointestinal malignancy. Expert Opin Biol Ther. 2007; 7(3): 397-404.

32. Evilevitch L, Westrom BR, Pierzynowski SG. CCK-B receptor antagonist YF476 inhibits pancreatic enzyme secretion at aduodenal level in pigs. Scand J Gastroenterol. 2004; 39(9): 886-890.

33. Cremonini F, Camilleri M, McKinzie S, et al. Effect of CCK-1 antagonist, dexloxiglumide, in female patients with irritable bowel syndrome: a pharmacodynamic and pharmacogenomics study. Am J Gastroenterol. 2005; 100(3): 652-663.

34. Zhou JJ, Chen ML, Zhang QZ, et al. Blocking gastrin and CCK-B autocrine loop affects cell proliferation and apoptosis in vitro. Mol Cell Biochem. 2010; 343(1-2): 133-141. 